\title{
THE JUST DESIGN AND USE OF MANAGEMENT CONTROL SYSTEMS AS REQUIREMENTS FOR GOAL CONGRUENCE
}

Natàlia Cugueró-Escofet

Josep M. Rosanas 


\title{
THE JUST DESIGN AND USE OF MANAGEMENT CONTROL SYSTEMS AS REQUIREMENTS FOR GOAL CONGRUENCE
}

\author{
Natàlia Cugueró-Escofet ${ }^{1}$ \\ Josep M. Rosanas ${ }^{2}$
}

\begin{abstract}
Management control systems (MCS) are designed to achieve the greatest possible goal congruence, where people pursue personal goals that conduce to the organizational goal. Use and design of MCS are crucial aspects for achieving goal congruence, but they are thought to be contingent to specific external situations. We attempt to analyse that justice in the design and fairness in the use of MCS are required to achieve specific levels of goal congruence independently of the situation.

We derive that there are two stable types of goal congruence, labeled maximum goal congruence (where the MCS design is just and the user is just) and minimum goal congruence (where the MCS design is unjust and the user is unjust); and two unstable types of goal congruence, in which goal congruence is occasional (unjust MCS design used justly) or perverse (just MCS design used unjustly).
\end{abstract}

Keywords: justice, fairness, goal congruence, management control systems.

\footnotetext{
${ }^{1}$ Researcher, IESE

${ }^{2}$ Professor, Accounting and Control, Crèdit Andorrà Chair of Markets, Organizations and Humanism, IESE
} 


\section{THE JUST DESIGN AND USE OF MANAGEMENT CONTROL SYSTEMS AS REQUIREMENTS FOR GOAL CONGRUENCE}

\section{Introduction}

Management control systems (MCS) are intended to motivate managers to ensure that organizational objectives are accomplished. They do this by acting as controlling and enabling devices (Simons, 1990, 1994, 1995a, b), and by rewarding and promoting people according to certain criteria. Usually, they are designed to achieve the greatest possible goal congruence, i.e., a situation in which by pursuing personal goals, people also pursue organizational goals.

The literature on management control has focused mainly on formalized MCS (e.g. see Chenhall, 2003; Davila and Foster, 2007; Davila et al., 2009). In general, however, wherever a control process is implemented, formal and informal controls coexist (Anthony and Govindarajan, 2003, p. 98). In the MCS literature, the study of MCS design has evolved to capture intangibles by including more complex indicators, using what is called a balanced scorecard (Kaplan and Norton, 1992, 1993). The balanced scorecard is thought to produce a greater alignment or congruence with organizational strategy (Epstein and Manzoni, 1997; Kaplan, 1996). In a four-case study, Chapman (1998) suggests that MCS have a complementary role as devices for coping with uncertain environments.

Contingency theoretical approaches to MCS situate them in a particular situation and moment in time (Chenhall, 2003), and have been the starting point of a literature that explains how MCS can be used to reduce uncertainty while promoting innovation (Bisbe and Otley, 2004; Davila et al., 2009; Davila, 2000), as learning devices to help particular strategies (Abernethy and Brownell, 1999), and to allow for entrepreneurial activities (Davila, 2005). Recent literature in the field has expanded the concept of MCS, exploring interactive uses (Abernethy and Brownell, 1997; Bisbe and Malagueño, 2009; Bisbe and Otley, 2004; Simons, 2000; Simons, 1995b), and enabling uses, based on the concept of enabling bureaucracy (Ahrens and Chapman, 2004).

Recent financial scandals have sparked debates on both MCS and the concepts of justice and fairness. Governments have been forced to intervene and inject public funds into some of the companies (mainly in the financial sector) that have been at the origin of the problems. Of course, the justification for the intervention has been to avoid worse consequences for the rest of society: if banks go bankrupt, savers lose their money; and if this were to happen on a large 
scale, it could become a national (and international) catastrophe. What governments have done, however, is unfair, because the consequences of the misbehavior of a few have been paid for by taxpayers who (as such) did not directly create the original problem. It is also unfair that those who created the financial problems at the social level (executives in the banking industry, mainly) have not directly suffered any consequence for their misbehavior. Rather, they have derived personal material benefits from their acts in the form of salaries and bonuses, which in the end they have not had to pay back. It can be argued that there is nothing illegal (hence, 'unjust'), in this situation; but obtaining private benefits by intentionally breaking the system and provoking a socialization of losses can be legal and unfair at the same time.

Interestingly, many problems have their origin in the incentive systems of the organizations involved. Incentive systems in particular and MCS in general have the power to generate such problems when they are used unjustly and when their design is unjust. For example, many mortgage salesmen had an incentive to sell mortgages. They were paid a commission based on the total amount of mortgages sold, no matter whether the people concerned could pay the mortgages back or not. This obviously created a short-term incentive for these mortgage salesmen that went against the long-term profitability of the bank they worked for. Also, many executives had an incentive to seek the short-term profitability of their bank, which was increased by selling those mortgages and accounting for them as a good asset. After a few years (or even months), when the crisis started and it became clear that the properties had a much lower value than the mortgage loans that had been granted, the further unfair consequence was that people lost their homes because they were unable to repay the loans.

The possible dysfunctionalities of MCS have been well documented in the literature. They range from very specific variables (e.g. budgetary slack and short term orientation, Merchant, 1985; Van der Stede, 2000) to much wider, dynamic frameworks, such as those of Gouldner (1954), Merton (1957), and Selznick (1949), as well as subsequent work by March and Simon (1958), Hopwood (1974), and Flamholtz et al. (1985). Hopper and Powell, in a paper that goes beyond these frameworks to examine their underlying assumptions (Hopper and Powell, 1985), provide many examples of dysfunctions found in the accounting literature, from the classical papers of Argyris (1953) and Ridgeway (1956) to, say, Ashton (1976), and Burrell and Morgan (1979). Dysfunctional here means inappropriate to the objectives of the organization, or to the people belonging to the organization. It follows that the results may be considered 'unfair' by someone else, inside or outside the organization. Thus, fairness towards someone is always an issue when dysfunctional behavior occurs (Cropanzano, 2001; Folger and Cropanzano, 1998).

For this reason, it is worth examining, on the one hand, the justice and, on the other, the use and design of MCS in order to see the role each may have played in permitting the abuses that may be the cause of the unfair consequences of MCS. In any company it is possible for a small group of managers to create and implement a MCS that pushes people in the wrong direction. By imposing ways of doing things, a MCS may benefit a small minority and create unfairness for the rest of the company.

In this paper, we study a way to address this problem and propose some solutions that have their origin inside companies, specifically regarding MCS. We attempt to show that taking justice into account in the design and use of MCS will result in greater goal alignment of individuals and, ultimately, more just consequences.

Specifically, we aim to show how the (in)justice of MCS design and the (in)justice of MCS use combine to create different levels of goal alignment. Different levels of goal alignment, in turn, 
lead to future states that are more or less stable and that feed back into the level of justice and fairness of MCS design and use. Just uses of justly designed MCS contribute to greater goal alignment, so that, in the long run, companies achieve better results and are less likely to generate unfair external consequences. Our main contribution is based on the distinction between formal and informal justice and on the fact that both types of ex ante justice are different from the fairness of the results. Then, as we will show, the combinations of formal and informal (in)justice lead to four states of goal congruence, of which we study the dynamics. Two of these states are stable: we label them maximum and minimum goal congruence. The other two are unstable: we label them perverse and occasional goal congruence. Each of the two unstable states evolves towards one of the two stable ones. We place importance on informal justice, as the presence of informal justice makes one of the unstable states evolve towards maximum goal congruence.

MCS have been studied mainly in the organizational justice literature, especially in relation to Human Resource Management systems (Folger and Cropanzano, 1998; Gilliland and Chan, 2001). It has been found that certain characteristics of HRM systems make people perceive them as being more or less just or fair, which makes people more or less motivated to contribute to the attainment of organizational goals. As Folger and Cropanzano point out, "when individuals perceive a lack of fairness, their morale declines, they become more likely to leave their jobs, and they may even retaliate against the organization. Fair treatment, by contrast, breeds commitment intentions to remain on the job and helpful citizenship behavior that go beyond the call of formal duties. In short, justice holds people together, whereas injustice can pull them apart" (preface xii, Folger and Cropanzano, 1998).

It is important for our purposes to clarify the use of two concepts. In the organizational justice literature, 'justice' and 'fairness' have been used interchangeably and typically are linked to measures of 'organizational justice perceptions', which are shaped by relevant aspects of system design, outputs and use (Adams, 1966; Adams, 1965; Colquitt et al., 2005a; Colquitt et al., 2005b; Leventhal et al., 1980; Thibaut and Walker, 1975a; Thibaut and Walker, 1975b; Thibaut and Walker, 1978). This research is important in that it considers fairness perceptions in terms of the effects a system generates. The focus, however, is on testing specific hypotheses in different settings, with promising incursions into MCS, especially in relation to human resource management.

In this paper we treat justice and fairness as separate concepts. In what follows we aim to clarify them. We use justice to refer to the ex-ante provisions of a system and the way the system is used. We consider two types of justice: formal justice, which refers to objective, rule-based aspects; and informal justice, which refers to the specific way in which a MCS is used. In contrast, fairness refers to perceptions of the ex-post consequences of a MCS and the way it is used. Thus, it is possible for a system to be designed in accordance with formal justice, and used in accordance with informal justice. Together, these two aspects will generate perceptions of fairness. From a legal perspective it can be argued that it is important to keep justice and fairness separate; to equate the two would be ethically or morally difficult to defend. There are many extreme examples of this, especially in unfair, authoritarian political regimes that apply the legal system strictly. While acting 'justly' (as defined by law), they are nevertheless 'unfair', from the point of view of an outsider, because of the consequences that enforcing their laws entail. In our view it is precisely the ability to stand back and consider the difference between justice and fairness that gives us room to critique. Indeed, this is a central point of our analytical model: a just use of the system can be sensitive to possible unfair consequences, thus allowing for future improvements to the system's design. This view is in line with studies by proponents of natural 
law, who argue that people have natural rights, beyond any legal system, and that once these natural rights have been detected, they must be included in the legal system and must be defended and implemented (Finnis, 1980). This, the proponents of this view argue, is the way to improve existing legal systems and achieve an ideal of justice closer to natural law.

There are two main reasons why many social scientists treat justice and fairness as interchangeable concepts. First, they argue that a system which has been designed to be just cannot produce unfair results (e.g. Rawls, 2003). Second, they are interested in perceptions of justice/fairness, and so they measure how people perceive the justice or fairness of outcomes and following the existing procedures. Specifically, they make no distinction between perceptions of justice and perceptions of fairness.

According to some current philosophical trends, justice and fairness have no meaning independent of human conceptions of justice and fairness. However, there are philosophical arguments for considering them as distinct and separate aspects. A concept such as justice or fairness can have no stability or depth if it is equal to an individual measure of justice or fairness, even if the perception is shared by several people. If we believe that what is just or fair is derived from what people perceive as being just or fair, we effectively exclude the possibility of misperception and cut short any discussion of what justice or fairness might be beyond an individual's first impressions. Of course, this also applies when a small group of managers implements a system (an internal rule in an organization) that is perceived as unfair: a majority shares the perceptions of unfairness, but what makes the perceptions real are the arguments behind them, not the fact that they are the perceptions of a majority.

Here again, our approach is close to that of natural law scholars, who clearly separate natural rights from implemented rights. This separation allows room for improvement. Human beings are holders of certain rights and those rights need to be defended by legal systems, independently of circumstances. As humans, we can recognize when actual systems of law produce fair or unfair results. We do this through perceptions and through moral reasoning. We therefore need to constantly update the justness of our legal systems by questioning them in terms of fairness. To give an example, slavery was seen as just and fair by Aristotle, when he proposed his theory of justice; but our updated concepts of fairness have morally questioned slavery, as it conflicts with the natural right of human beings to equal freedom (Aristotle, 2000; Finnis, 1980).

Regarding perceptions, research on organizational justice has suggested that people perceive certain aspects of justice to be the same for everyone, regardless of personal circumstances and broader contextual embeddedness. In fact, all constructs of fairness perceptions rely on empirical evidence that shows them to be statistically significant, which means that we can falsify the hypothesis that they do not exist (Cohen and Greenberg, 1982). At the same time, people perceive the injustices of actual legal systems. This clearly shows that people can morally detect what is unfair and needs to be updated in legal systems in order to make them more just. It is precisely the fact that things can be perceived to be unjust and the arguments we can use to defend such perceptions that makes perceptions interesting; at the same time, it also makes it impossible for perceptions to stand on their own, without further consideration and deliberation.

In our study we consider the concept of justice because we are interested in the ex-ante provisions of MCS and the use of such systems. We consider that justice in MCS design and justice in MCS use should be a set of minima that combine and conduce to different types of goal congruence. 
We aim to show that different levels of justice in MCS design and use can lead to different levels of goal congruence or goal alignment. There is empirical evidence that certain aspects of justice perceptions link to MCS (see for instance Coletti et al., 2005; Hartmann and Slapnicar, 2009), but there has been no conceptual analysis (for evidence look at Cugueró-Escofet and Rosanas, 2011). Our research serves three purposes. First, it may start a constructive debate on the appropriateness of our proposal, which is badly needed after the recent financial scandals, as our opening example clearly shows. The current financial crisis has brought MCS design and use into question, and we propose ways in which MCS design and use can be improved. Second, it paves the way for empirical research into how close or far actual MCS are from our conceptual proposal, in order to see whether justice is a characteristic that escapes from the argument proposed by contingent theory, namely, that everything in MCS is contingent. Third, we can look at why actual MCS match, or fail to match, our proposal and consider how they could be improved.

Apart from these general objectives, we also fill two important gaps. First, we reintroduce the concept of goal congruence into the study of MCS and show how justice of MCS design and justice of MCS use are necessary for achieving certain types of goal congruence. The main purpose of MCS has been to help achieve goal congruence. This general objective of goal congruence is complementary to the more recently identified objective of helping companies cope with strategic risks and uncertainties. Recent literature has concentrated on how MCS can be designed to favor particular strategies, such as promoting learning through budgeting processes (Abernethy and Brownell, 1999), promoting innovation (Davila, 2000), or enabling entrepreneurial success (Davila et al., 2009). This is not at odds with the ultimate objective of achieving congruence of individual and organizational goals, as even when a MCS is used to decrease uncertainty, it still needs to achieve some degree of alignment between the interests of individuals and the interests of the organization (Gottschalg and Zollo, 2007). Ultimately, management control systems need to make people behave in ways that lead to the achievement of organizational goals.

Second, we introduce the discussion of how justice is a requirement of MCS in order to attain goal congruence. The organizational justice literature has investigated which aspects of fairness create the strongest perceptions of fairness and so elicit the best reactions, thus helping to achieve organizational goals (Colquitt et al., 2001; Cropanzano et al., 2007; Greenberg, 1987). We know that perceptions of fairness can be achieved through specific measures, which may be motivated by a desire to create real justice but which can also be a mere impression management exercise aimed at managing perceptions, with no attempt to improve substantial justice (Ashford, 1992; Greenberg, 1990a; Greenberg et al., 1991; Greenberg, 1988; Tedeschi and Reiss, 1981).

We are not the first to suggest that fairness is an important requirement of MCS use. In the theoretical control literature, fairness and goal congruence are considered the main criteria for evaluating MCS use (Vancil, 1973). This provides a first starting point for our argument here because even though Vancil does not explain how fairness and goal congruence are linked, he attempts to bring the two concepts together and define them in more depth. We stress, however, that this is almost the only example we have found in the literature where fairness and goal congruence are linked (Cugueró-Escofet and Rosanas, 2011).

In this paper we proceed as follows. First, we explore the concepts of MCS and justice. Second, we identify the requirements for a MCS design to be just and for the use of a MCS to be fair, and derive a set of propositions for just MCS design and use. Third, we propose a normative model of how justice needs to be taken into account in the design and use of MCS in order to produce four possible types of goal congruence. In doing this we show how the presence or absence of justice in design and use leads to different types of goal congruence. 


\section{Management control systems and goal congruence}

According to Otley and Berry (1980), control is a much neglected subject. Thirty years on, the situation is hardly any better, in spite of technical progress in tools such as the Balanced Scorecard or better information based on advances in IT (Kaplan and Norton, 1992, 1993). In the same article, Otley and Berry quote Tannenbaum (1968) as saying that "an organization without some form of control is impossible", which should be only too obvious. Managerial tasks entail setting goals, monitoring execution, evaluating results, and allocating rewards and punishments. All these tasks are part of the management control process.

Traditional, highly formalized control systems are particularly suitable for cybernetic systems, where there are more certainties than uncertainties. In rapidly changing, highly uncertain environments, however, a traditional MCS can become a straightjacket. Hence, informal structures are needed to influence the control process. To allow for flexibility, the behavioral literature on MCS has considered how these systems can be used to cope with uncertainty (Chapman, 1998). The concept of enabling bureaucracy (Adler and Borys, 1996) has introduced different uses of MCS best suited to dealing with uncertainty (Ahrens and Chapman, 2004).

The four levers of control described by Simons (1995b) are labeled beliefs, boundary, diagnostic and interactive control systems (Simons, 1995b). This framework has been used in several papers as types of MCS, and to test how managers seek to manipulate culture and beliefs for management control purposes (Marginson, 2002; Mundy, 2010; Simons, 2000; Widener, 2007). In general, culture and social controls have been investigated as having influence over managerial behaviors (Hopwood, 1974; Johnson and Gill, 1993). Research has also addressed interactive uses of MCS.

Formal and informal controls coexist, as the informal organization creates informal controls that have an impact on people (Anthony and Govindarajan consider the informal organization as a set of relationships). However, the impact of the informal organization on management control has been sadly neglected (Anthony and Govindarajan, 2003, p. 102). Also, Barnard included the informal organization in his groundbreaking book, The Functions of the Executive (Barnard, 1938). Informal controls may give rise to concerns about arbitrariness, and for that reason a body of literature has concentrated on how MCS can include subjectivity that removes arbitrariness (Bol et al., 2010), or other variables, such as organizational justice in procedures, that make subjectivity unnecessary (Burney et al., 2009). In general, even in organizational startup situations, formal controls have been seen as conducive to organizational success (Davila, 2005; Sandino, 2007), which is to say that informal controls alone do not suffice. Also, extremely formalized control systems (Adler and Borys, 1996) can be so inflexible as to have no enabling uses (Simons, 1995a).

As stated before, goal congruence is "the central purpose of a management control system" (Anthony and Govindarajan, 2003, p. 98). Having made this central statement, Anthony and Govindarajan go on to say that "in a goal congruent process, the actions people are led to take in accordance with their perceived self-interest are also in the best interest of the organization". They recognize that usually, in an imperfect world, perfect goal congruence does not exist, but insist that MCS need at least "not to encourage individuals to act against the best interests of the organization" (Anthony and Govindarajan, 2003, p. 98). In a more practical vein, they argue that in order to evaluate any management control practice, there are two crucial questions to be answered: 1) What actions does the management practice motivate people to take in their own self-interest? 2) Are these actions in the best interest of the organization? 
Vancil (1973) does not use the expression 'congruence' but proposes that "the controller must select the objectives and measurements in such a way that a good decision by any manager is also a good decision for the corporation as a whole" (Vancil, 1973, p. 77). Vancil thus defines goal congruence in terms of how control systems need to be designed by a controller.

In the economics literature, goal congruence was labeled 'incentive compatibility'. Of course, the economics literature assumes perfect (unbounded) rationality on the part of the agents and takes only tangible economic variables into account, implicitly assuming them to be perfectly measurable. The term 'incentive compatibility' was coined by Hurwicz (1972) in a classic article in which he tried to answer the question of how an institution needs to be designed when selfinterested individuals might try to manipulate economic variables to their personal advantage. Incentive compatibility is, of course, a desirable characteristic; but it is limited to perfectly defined aspects of MCS. These systems need to have tangible, quantifiable variables, excluding, for instance, unselfish cooperation in organizations. Incentive compatibility is a necessary condition, but it is not sufficient to align individual and organizational goals. MCS should be designed in such a way that goal congruence increases over time, or at least does not decrease.

In the early days of the more behaviorally oriented management control literature, some researchers classified organizations into normative, instrumental or coercive, depending on whether goals are perfectly aligned, partially aligned, or totally misaligned (Otley and Berry, 1980). In practice, most organizations are close to the instrumental model, so the real problem is finding solutions that provide inducements to individuals to contribute to the organization's goals (Barnard, 1938), thus increasing the probability that individuals will act in ways that lead to the attainment of organizational goals. A recent version of the term was labeled 'organizational interest alignment', defined as "the degree to which the members of the organization are motivated to behave in line with organizational goals” (Gottschalg and Zollo, 2007, p. 420).

\section{Justice and fairness in MCS. Goal congruence}

Justice and fairness, as we stated in the introduction, have gained prominence recently and, as we will show, can be important concepts in the operation of a MCS. Justice has been associated with legal justice (Aristotle, 2000), and with ideas close to practical wisdom (Aristotle, 2000). Justice is parallel to characteristics of MCS design and managerial use. Fairness has a perceptual dimension, relating to how people see systems and the decisions which those systems produce.

Next, we discuss the main philosophical arguments about the importance of considering justice as a requirement of formal and informal systems and their use. We also consider how social science has studied perceptions of justice and fairness in order to show major contributions in relation to the consequences of the formal and informal aspects of control systems and their use. These two paths of inquiry (philosophical and empirical) are in fact interrelated, because empirical research has been used to test the extent to which certain aspects of control systems and their use were present or not when studying people's perceptions. In general, though, and applied to organizational settings, organizational justice in social science has been studied mainly in an empirical way.

Then, we will show what we consider to be the justice requirements of MCS design. Finally, we turn to the problem of what is required for MCS use to be considered just. 


\subsection{A conceptual view of justice applied to MCS}

One of the first analyses of justice in philosophy is to be found in Plato (Plato, 2006). Plato conceives of justice as a societal device used to protect people from abuse by the powerful. He proposes that a well ordered society needs to include justice, instead of the "rule of the stronger", which is the natural state of affairs if no limits are applied. Plato's pupil, Aristotle, argues for a more systematic approach to justice, in terms of conditions for societal systems to guarantee arrangements that lead to happiness, which is to be considered the ultimate end.

We consider primarily Aristotle because he takes a systematic approach to justice as a fundamental aspect of social systems that encompasses the 'design' and 'use' dimensions we are concerned with in this paper. Furthermore, Aristotle is at the origin of most of the conceptual applications of justice in current systems of thought applied to management (Adams, 1966; Adams and Freedman, 1976; Adams, 1965; Goodman and Friedman, 1971; Leventhal et al., 1980). Aristotle's main thoughts on justice are found in the fifth book of his Nicomachean Ethics (Aristotle, 2000). As our aim is to go back to the basics in order to apply the basic concepts to the MCS literature, we think that a systematic approach to Aristotle's system of thought regarding justice and fairness is crucial for our analysis.

The framework established by Aristotle clearly distinguishes between three concepts: justice of the legal system; justice associated with the virtue of using these systems in accordance with the law (the virtue of the just); and fairness associated with adapting the system to specific situations when applying it (the virtue of the fair). Justice of the legal system is a quality of the system itself, in the sense that the system includes specific criteria to help guarantee fair distributions and retributions. Justice and fairness are associated with the quality of applied justice, and therefore with the use of the system, which reflects the inclusion of contextual circumstances to change the decisions made using just systems, and might originate possible future system improvements. Following Aristotle, justice and fairness are needed because it is not enough to consider justice only as a static aspect of a system. Justice is an aspect of the system, but at the same time, together with fairness, it is also a virtue that includes willingness to follow the spirit of the law, i.e., not blindly but adapting it to take account of contextual and personal considerations, resulting in a personalized application of the system. Justice thus encompasses what is lawful (justice of the system design), willingness to follow the law (justice as a virtue of the system user), and willingness to achieve just and fair results for people (fairness as a virtue of the system user) (Aristotle, 2000, Book V). Even if Aristotle is not clear enough in separating the concepts of justice and fairness, it seems that justice is close to 'legality' (justice associated with current regulations) and willingness to adhere to a legal system (justice as a virtue), while fairness is more dynamic and clearly closer to how justice is implemented, so as to generate fair outcomes. A system, whether just or unjust, can therefore produce fair or unfair results. Following Aristotle, however, a just design, used with the practical virtues of justice and fairness, will tend to produce fair results - perhaps not immediately, but after some conflict, which will then give rise to proposals for changes to the system.

Aristotle talks about justice as a virtue, one that is part of a person's character (i.e., willingness to use the legal system to create fair results). He defines justice as "that kind of state of character which makes people disposed to do what is just and makes them act justly and wish for what is just" (Aristotle, 2000, p. 109). In his view, justice is the greatest human virtue and the one that comprises all the rest: "in justice is every virtue comprehended" (Aristotle, 2000, p. 111). Justice is also complete in the sense that it is the only virtue that is needed in cooperation; in other words, justice is the virtue that people need to have when engaging in

8 - IESE Business School-University of Navarra 
cooperative acts and therefore is particularly important in organizational contexts. Aristotle stresses the person's will as part of this virtue because "a man is just when he acts justly by choice" (Aristotle, 2000, p. 129).

Simplifying somewhat, justice has been studied following two different paths: that of Plato and the followers of justice as an ideal, and that of Aristotle and the proponents of justice applied in more realistic terms. Nowadays, the debates between the real and ideal continue, as Flyvbjerg points out when discussing the ideas of Habermas and Foucault, "Foucault as a practitioner of phronesis... with the emphasis of phronesis on practical rationality and common sense knowledge" (Flyvbjerg, 1998, p. 225), and Habermas being the "most prominent living exponent of a universalistic and theorizing tradition from Socrates and Plato" (Flyvbjerg, 1998, p. 228). After Aristotle, Aquinas proposed a version of justice along very similar lines (Aquinas, 2002).

The discussion of justice later entered the societal arrangements arena. Two main approaches can be found: libertarian and utilitarian. For libertarians, the state is reduced to a minimum. Property rights are acquired and transferred, and with them, those justice rights associated with their public societal defense (Locke, 1952). The libertarian view is normative because as long as morally mandatory acts are performed, consequences are good (the right antecedes the good). For utilitarians, the important thing is the consequences of specific societal designs. Utilitarians argue that as long as the consequences of particular arrangements are considered good, those arrangements are right (Bentham, 1948).

A different way of classifying theories of justice is according to whether they attempt to be normative or explanatory. We thus find normative and positive theories. Normative theories consider which arrangements are necessary in order to arrive at a just society. There are two main groups of normative theories of justice: theories focused on the content (Finnis, 1980; Kant, 1981), and theories focused on the procedures (Habermas, 1990; Rawls, 2003; Rawls, 1971).

Finnis considers justice as a means to guarantee a set of natural rights. In his view, some rights are universally defensible independently of any particular societal arrangement for a given point in time (Finnis, 1980). The basic idea is to assert which are the rights that cannot be neglected. Looking at the terrible things that some human beings have done to others, it seems more defensible to look at Finnis's proposal as a set of minimum rights, rather than as a set of universal laws. Kant's defense is more aligned to moral imperatives that also need to be followed in order to lead a virtuous and moral life (Kant, 1981). Kant grounds his arguments on the necessary inclusion of morals as principle-based and metaphysical, proposing his categorical imperatives: "If you want A, then do B". Kant has been criticized for being unrealistic, dogmatic and idealistic, and for offering little practical guidance for implementation, blindly focusing on principles of morals (Chomsky and Foucault, 1974).

Rawls deserves special mention, as he has been very influential. Rawls considers that justice and fairness are the same. According to him, a just design will produce fair results. In this sense, following our previous classification, he is utilitarian, normative, and focused on procedures. John Rawls offers a definition of justice as a rational foundation for a well ordered society, assuming that "...a society is rightly ordered, and therefore just, when its major institutions are arranged so as to achieve the greatest net balance of satisfaction summed over all the individuals belonging to it..." (Rawls, 1971, p. 22). Rawls finds it necessary to include the protection of some rights for the powerless (a parallel to Plato can also be noticed here); but he mostly justifies the current state of affairs and does not offer a way to examine in depth how organizations can contribute to justice or injustice. There are at least two important aspects of 
Rawls' theory that make it difficult to apply. The first is that Rawls does not answer the basic question of why an organization should act justly. In the basic capitalistic approach, organizations maximize profits and extract surplus value from society, and in doing so they do the opposite of what Rawls' theory suggests. The second aspect is that the individual's perceptions and moral reasoning are ignored in his proposed theory, although they are important, as individuals usually follow their own perceptions and reasoning in deciding whether a particular societal arrangement is fair or not. Offering a closed concept of justice that works now and forever seems inappropriate because it ignores the need to distinguish between justice and fairness in order to explain how justice evolves over time.

Habermas proposes an intersubjectivity approach to justice and argues in his theory of communicative action and discourse ethics that "the communicative rationality includes connotations of a noncoercively unifying, consensus-building force of a discourse in which the participants overcome their at first subjectively based views in favor of a rationally motivated agreement" (Habermas, 1987). Human social life, according to Habermas, is a process of reciprocal understanding that is universal because people cannot avoid it. The human being is defined as homo democraticus, and "nothing coerces anyone except the force of the better argument" (Habermas, 1990). Some requirements of discourse ethics are thus necessary in Habermas's thinking: all parties must be included; all of them can present and criticize arguments; they must be willing to empathize with each other; they must eliminate power differences; and intentions and goals need to be explicitly recognized. This is an ideal type of theory that is helpful to constitutional writing but not to implementation (Flyvbjerg, 1998). Habermas it is a "top-down moralist as concerns process: the rules for correct process are normatively given in advance, in the form of the requirements for the ideal speech situation. (...) But a bottom-up situationalist because what is right and true in a given communicative process is determined solely by the participants" (Flyvbjerg, 1998, p. 214).

On the other side from the normativists we find researchers who focus mainly on actual events. Within this group we find, at one extreme, the positive theorists. For them, justice is absolutely dependent on societal arrangements at a given point in time. They consider that what people find good, will be right (Gauthier, 1986). Apart from this very relativistic approach, we can find authors who revisit Aristotle and, while far from being purely ideal, are also far from being relativistic and purely consensual or contractual. In their view, justice cannot not be merely an agreement as to what we think is just, but nor is it an ideal of what ought to be just independently of context and local circumstances (Chomsky and Foucault, 1974; Foucault, 1988). New Aristotelians are to some extent normative in the sense that they put what is right before what is good, and because they also think that consensus does not define what is just. At the same time, they also consider enlightened practical wisdom important and think that it, too, is contextual and dependent on personal circumstances (they give importance to conflict and virtuous practice). These new Aristotelians base justice on phronesis and are very close to reproducing Aristotle's ideas (Chomsky and Foucault, 1974; Foucault, 1988).

Habermas relies on constitution writing and development. Following Flyvbjerg (1998), Habermas proposes the force of the better argument as the rational solution for justice as an output of a democratic process (Habermas, 1990). Flyvbjerg contrasts Habermas with Foucault, who proposes a focus on reality and context-dependent solutions and argues for a justice that is found after necessary power struggles (Flyvbjerg, 1998, p. 227). Foucault proposes the force of conflict to fight against established ideas of justice that produce actual unfair arrangements for minorities. In this paper we include the ideal view of Habermas when considering justice in MCS design (a constitutional view), and Foucault's new Aristotelian view when we assess MCS

10 - IESE Business School-University of Navarra 
use according to justice criteria. Other philosophers, such as Derrida, use the concept of 'undecidability' to suggest that deciding is not just weighing up and choosing amongst certain pre-conceived internal options, i.e., making a decision is not the same as preparing oneself to decide. Derrida suggests that, for a decision maker to be truly responsible for a decision, the decision should surprise the decision maker and should go beyond calculative reasoning (Derrida, 1997, p. 69). This is very close to our concept of informal justice, which requires that subjects update their justice reasoning based on the unfairness they witness or perceive, or for which they are held responsible. This is in line with Derrida's general idea regarding ethical behavior, which includes being forever open to possibilities, rather than taking a definitive position (Derrida, 1995). Kelsen also separates the formal system of law (an idea close to our 'formal justice') from fairness (which Kelsen considers subjective in nature). Kelsen is against natural law, and as a positivist separates facts (positive law) from justice (which he considers an irrational ideal) (Kelsen, 1945).We find that Kelsen affords important insights into the process by which laws are validated to form a well-established hierarchy of norms. But what about the norm that validates the rest, i.e., the 'constitution'? How is the constitution validated? Kelsen seems to have no answer to this question. It is quite clear, therefore, that this constitutional norm must be inspired by natural rights, even though Kelsen argues that justice (as an 'irrational ideal') cannot be cognitively understood.

Turning to the justice/fairness debate in accounting, there are several papers worth discussing here. Regarding the importance of including fairness concepts in accounting we find the conceptual work of Williams (1987) and, four years later, a comment made by Pallot (1991). Williams suggests that the principle of decision usefulness is incomplete for organizing accounting research. He submits that fairness must be included in accountability and distribution, as a necessary condition for making the value judgments in accounting research explicit. Williams points out that accounting problems are distributive in nature and that "fairness is the concept required" and "deliberations involving fairness in accounting are actually inescapable” (Williams, 1987, p. 178).

Williams stresses the point that efficiency criteria and market justice have consequences in terms of fairness judgments in accounting; but the accounting literature leaves efficiency criteria and market justice implicit, and so obscures their rational arguments. Williams argues that the assumptions contained in fairness judgments should be made explicit, so as to see possible alternatives of choice. This is very close to the idea of discourse ethics proposed by Habermas (Habermas, 1990). Williams argues that attention to the concept of fairness needs to be included in the design of accounting devices and in the use of such devices, stressing the fact that the "process needs to be characterized by the discounting of prejudice in any balancing of conflict", and that "the accountant as evaluator attempts to adopt a perspective of impartiality" and needs to "recognize that the production of accounting data involves consequences that may be judged as unfair" (Williams, 1987, p. 171). With these arguments, Williams also includes system use and context dependencies that are closer to Foucault's idea of adapting systems to produce fair outcomes, not merely proposing normative requirements to be followed (Foucault, 1988). Williams goes on to say that "a profession becoming more scientific does not necessarily require abandoning moral decision making and the cultivation of modes for doing so" (Williams, 1987, p. 185). In his view, fairness has potential implications for a possible development of accounting epistemology.

Commenting on Williams' work, Pallot stresses that competing ethical frameworks suggest different attitudes towards the question of fairness (Pallot, 1991). She stresses that ideas about fairness have evolved: whereas the neoclassical paradigm ignores whether a bargain is fair or

IESE Business School-University of Navarra - 11 
not, rights-based approaches, such as the one proposed in Rawls' Theory of Justice, are mainly individualistic but include accountability (Pallot, 1991, p. 203). Contracts are by their very nature incomplete (Sandel, 1984), and there is a need to include concepts based on a shared understanding of our common life as members of a society.

Luft (1997) deals with the concept of fairness as a goal different from self-interest. In Luft's approach, fairness is a motivation, rather than a system requirement or a characteristic of the outcome itself. She claims that the widely represented self-interest preference models fail to show the concern for ethics that current managerial practice reveals. Luft's paper is related to the literature on organizational justice, which has shown that justice and fairness are great motivators for people (Cropanzano et al., 2005).

More recent thinkers apply justice concepts to organizations. They have done this by expanding Aristotle's proposals (see for instance Adams' equity theory, based on Aristotle ideas of equity, Adams, 1963, 1965). Organizational justice scholars have studied both fairness and justice perceptions from an individual point of view (Adams, 1963, 1965; Thibaut and Walker, 1978). We will discuss some of their main findings next.

Organizational justice has been studied in order to explain justice perceptions linked to many organizational variables (as an example of surveys of the field, see, for instance, Fortin, 2008; Greenberg, 1987). In this literature, the terms fairness and justice are used interchangeably. For that reason - and to distinguish this literature from our concepts of formal justice, informal justice, and fairness - we shall avoid using 'justice' as far as possible and shall use 'fairness' instead, except when referring to particular types of fairness perceptions, or where certain empiricists have focused on dimensions of fairness that go beyond mere perceptions of results. As we understand it, this literature deals mainly with a concept that it is close to the one we have termed 'fairness', i.e., linked to an outcome and therefore ex post and based on individual perceptions.

Major analyses in the field have been directed towards understanding what fairness/justice is (Adams, 1963, 1965; Cropanzano and Ambrose, 2001); why people have fairness/justice motivations (Cropanzano et al., 2005; Folger, 1998); how judgments are formed (Cropanzano and Folger, 1989; Folger, 1986; Folger and Cropanzano, 2001); and the consequences of different fairness perceptions and justice policies applied in organizations (Cropanzano, 1993). Some research has concentrated on how to establish guidelines to help managers improve the fairness perceptions of employees (Cropanzano et al., 2007). People care about fairness, and many desirable organizational outcomes may be adversely affected by perceptions of fairness. Caring about employees' fairness perceptions therefore seems likely to pay off, and establishing policies to improve those perceptions can be considered proper managerial behavior (Cropanzano et al., 2007).

This means that, subjectively, people care about the treatment they receive from formal systems, on the one hand, and from managers, on the other. The most widely used model of fairness perceptions has been tested by Colquitt (Colquitt, 2001). Colquitt found four justice facets: 'procedural justice', 'distributive justice', 'interpersonal justice', and 'informational justice'. Distributive justice is defined as the fairness perceived depending on the outcomes received; procedural justice, as the perception of fairness formed depending on the procedures used (Blader and Tyler, 2003); interpersonal justice, as the quality of interpersonal treatment (Bies and Moag, 1986); and, finally, informational justice depends on the explanations received by the decision maker (Shapiro et al., 1994). All facets can be combined to lead to overall fairness perceptions, even if different facets are found to create different effects (Colquitt, 2001). 
The approach to justice/fairness in the management literature has been largely empirical. Initially, empirical models drew upon philosophical theories of justice, especially the concepts of Aristotelian thought (Greenberg and Bies, 1992). Recent studies have usually built directly on empirical findings, without explicitly stating what philosophical theories are at the basis of their findings (see a recent study of Long et al., 2011).

Many organizational justice scholars have shown interest in core topics of management and control. There has been considerable organizational justice research in organizational settings and some of this research has focused on HRM systems (Folger and Cropanzano, 1998; Gilliland and Chan, 2001). A recent, different way of looking at fairness perceptions is the concept of fairness monitoring, introduced in a recent paper by Long et al. (2011). Fairness monitoring is people's effort to gather and process fairness information in order to make sense of their organizations. Depending on the type of controls individuals perceive in their organizations, they start monitoring one type of fairness or another (Long et al., 2011). Justice and fairness have also been found to be clear motivators for people to behave in ways that are more beneficial to the organization (Cropanzano et al., 2001). In general, people are motivated for fairness/justice out of instrumental motivation, a sense of belonging, and purely moral motives; these three types of motives can appear at the same time, as people usually are motivated by all three aspects, each of which may be more or less salient. We have already mentioned that some accounting scholars propose the fairness motive as an alternative to self-interest (Luft, 1997). In this sense, there could be a justice/fairness motive linked to the morality of fairness and justice proposed by Cropanzano et al.

Organizational justice scholars have recently declared the need to go back to basics and reformulate simple and informative concepts in order to build better models of justice and fairness in organizations. We start by examining the requirements of a just design, and the propositions that follow from it. We use 'just' for design and use, even though some researchers have used 'fairness' for both use and results (Aristotle, 2000). In our approach, fairness is more useful as a measure of ex post results, whereas here we are focusing on ex ante conditions and so basically are using the concept of justice. For example, there could be a court system, in which certain procedures must be followed in order to guarantee formal justice, e.g., the right not to incriminate oneself (an aspect of formal justice). There will be a judge or jury which, by examining the evidence, will decide on the penalty to be applied and, with some degree of subjectivity, the degree of penalty to be applied (informal justice). The decision or result is then applied to a person, who may see the decision as either fair or unfair. But there are also third parties, who may likewise perceive the decision as fair or unfair (fairness). All three dimensions, formal justice, informal justice and fairness, are necessary and different, especially in the case of an organization, where the specific rules are not legally mandatory and there is no judge (the manager acts as a judge of sorts but cannot be totally impartial, as he/she has something at stake in every decision he/she makes). A bonus, for instance, is sometimes shared between the manager and his/her subordinates, so the more the subordinates get, the less is left for the boss. That it is why it is crucial to clearly distinguish between fairness, on the one hand, and formal and informal justice, on the other, as this distinction makes it possible to assess results and highlights the need for informal justice on the part of the manager. For a judge, sometimes it is easier to remain detached from informal justice and focus on strictly applying the law (formal justice).

After that, we shall consider the limitations of a just design, and how a just use is also needed. Then, we formulate some specific propositions on justice in the use of a MCS. Finally, we draw a model of how the two types of justice (formal in relation to the design, informal in relation to 
use) combine, giving four states of goal congruence, for each of which we provide a series of propositions in order to look at the dynamics that are generated.

Propositions about what MCS design and use should be like in order to be considered 'just' are normative in nature; our propositions therefore come mainly from conceptual arguments. However, we also use some empirical evidence, which can be useful, although we caution the reader that such evidence is used as an auxiliary element.

We think it is possible to empirically test whether a particular combination of just/unjust design and use does actually result in a particular goal congruence state. We believe that each combination (of just/unjust design and use) will lead to a particular state, which will evolve in the way we describe. Although our purpose here is to set up the model and provide sound arguments to support it, we believe that future empirical research may find empirical evidence for the existence of these four states and their pattern of development. This empirical research could be done using cross-sectional data, but we think it would be more useful to find longitudinal data, as our approach also considers the dynamics of the four states.

\subsection{Justice in MCS design: Formal justice}

Organizational goals are a very complex aggregation of individual goals (Simon, 1964). Organizations must avoid arbitrariness (Leventhal et al., 1980). In general, involving individuals in the budgeting process has been one of the tenets of recent literature on participative budgeting (Chenhall, 1986; Chenhall and Brownell, 1988; Shields and Young, 1993). Procedures that allow individuals to take part in the process is also one of the requisites of the procedural justice literature (Lindquist, 1995). Giving people a say and offering explanations during management control processes has been found to have a positive effect (Libby, 1999, 2001; Van den Bos et al., 1996). Generally speaking, managers react more positively when procedurally just management control systems are implemented (Taylor et al., 1998). Findings suggest that management control system designs that are developed following due process lead to greater procedural justice perceptions (Taylor et al., 1995).

Subsequently, research moved towards a better understanding of the mechanisms by which a formalized budgeting process can create fairness perceptions, and how such mechanisms lead to higher performance. Wentzel (2002) argues that these mechanisms can be explained following a two-step process. The first step concentrates on how participation in the budgeting process increases fairness perceptions. The second step shows that those fairness perceptions lead to greater goal commitment (goal congruence) on the part of managers and thus to greater overall performance (Wentzel, 2002). Generally speaking, perceptions of justice coming from the management control system lead to more positive behavior towards the organization and the supervisor (Thurston Jr. and McNall, 2010). More recent empirical research has included elements of procedural and distributive justice as variables mediating between strategically oriented management control systems and performance (Burney et al., 2009). Researchers have used distributive and procedural justice constructs that show formal fairness aspects of the management control systems. We summarize our discussion in the following proposition:

Proposition 1: A just design of a MCS should set goals in a way that integrates individual goals.

Another important requirement regarding the justice of a MCS is how the rules of the game are established. Regarding MCS as evaluating and rewarding mechanisms, goals and performance assessments across subunits need to have certain characteristics; for instance, assessment procedures need to be consistent (Leventhal et al., 1980). This means that people need to know 
in advance on what criteria they are going to be judged and rewarded (Van den Bos et al., 1996). Consistency also implies that procedures must not contradict each other, and what is expected of people must be in line with the contribution they are prepared to make (Leventhal, 1976). Finally, the norm of distributive justice should be transparent and understandable (Sandel, 1984; Sen, 1992). In summary,

Proposition 2: A just design of a MCS should distribute resources and responsibilities among subunits and evaluate subunits according to the real achievements of each subunit and the competences of its staff, in accordance with rules of the game that are explicitly established ex ante.

Management control scholars have always recognized that managers must be assessed on factors they are able to control (the so-called controllability criterion). One of the proponents of this criterion is Vancil (1973), who argues that evaluation based on controllable performance can be considered to be 'fair'. He also explains that "a manager must believe that measurement encompasses all the factors he can control and excludes those over which he has no control" (Vancil, 1973, p. 77). Indeed, controllability is one of the tenets of management accounting, in spite of possible dysfunctionalities (Demski, 1976). At the same time, organizational justice scholars consider controllability to be a procedural design requirement of any process (Colquitt, 2001; Leventhal et al., 1980).

Recent studies have focused on acquiring a better understanding of this controllability principle (Giraud et al., 2008). Findings suggest that managers are willing to accept being evaluated on factors they can influence but do not necessarily fully control. Moreover, they clearly distinguish between internal and external factors and tend to be more concerned about controlling the internal ones (Giraud et al., 2008). It is clear that to have perfectly controllable ex ante variables is impossible, and that a degree of flexibility may foster creativity and be a desirable characteristic of a MSC (Giraud et al., 2008). In summary,

Proposition 3: A just design of a MCS should include some form of controllability criterion, meaning that managers should only be evaluated on elements over which they have some influence.

Rewards are a crucial aspect of management control systems and are recognized by the literature on distributive justice. It is recognized that people need a minimum reward, below which it is difficult to have a decent standard of living (Aristotle, 2000; Sen, 1992). Therefore, it seems necessary to establish a 'just' minimum reward when designing management control systems. Various contributions in the literature argue for a social minimum to guarantee basic needs and prevent social exclusion. Empirical research has acknowledged that establishing such a minimum is appropriate (Scott et al., 2001). Rawls was explicitly considering that this minimum in some cases has to be maximized, all else being equal (Rawls, 2003; Rawls, 1971). The management control literature has not called for a social minimum reward, but minimum wages have been established by law.

Besides this social minimum, some researchers have warned that attention must be paid to pay inequalities, as they have harmful effects on those concerned and ultimately also on the companies that rely on systems that create such inequalities (Siegel and Hambrick, 2005). There is a tension between the need to design systems that compensate according to performance and the fact that creating huge pay differences makes low performers feel unfairly treated, which affects their actions. Low performers end up believing there is nothing they can do to attain higher levels of performance in the future, and start to feel detached from the organizational purpose (Siegel and Hambrick, 2005). Usually, research on formal systems has concentrated on 
the first part of this tension, i.e., rewarding according to merit, but recently the focus has turned to examine the effects of pay inequalities, which are important and cannot be ignored (Fredrickson et al., 2010). In summary,

Proposition 4: A just design of a MCS should establish a minimum reward to be received by all participants, and must set a limit to pay inequalities.

No system is perfect and important variables are not perfectly measurable, so MCS need to provide some rules regarding this assumption of not being perfectly designed. In terms of justice, this means explicitly recognizing flaws in management control systems by establishing formal means of repairing any injustices that may be created (Wenzel et al., 2008). Organizational justice scholars have found that the main motivation, after an injustice occurs, is the willingness to find means of reparation (Conlon et al., 2005). MCS design needs to acknowledge that a MCS cannot deal with all possible situations and that no MCS design can take all possible future states into account. Furthermore, research has found an appropriate managerial behavior to promote ways of making reparation (Cropanzano et al., 2007; 0'Malley and Greenberg, 1983). Thus, applicable reparation policies and the option of repairing the system need to be explicitly included in the system's design. In summary,

Proposition 5: A just design of a MCS should include formal means of repairing injustices and should provide mechanisms for changing the system.

\subsection{Justice in the use of the MCS: Informal justice}

The design of a MCS is important, but we need to go beyond the design to look at the use of the MCS. In the MCS literature we find three different arguments for doing so. The first has to do with the fact that MCS that rely exclusively on formal controls have generally been shown to be suboptimal when the output is not measurable and the activities performed are not perfectly observable (Ouchi, 1979). This applies to MCS that are designed to follow only justice formal requirements, which we have shown in the previous section.

A second argument comes from incomplete contracts theory. Under bounded rationality it is impossible to establish a contract that anticipates every possible contingency that may arise from future fulfillment of the contract (Milgrom and Roberts, 1992, p. 256). The informal dimension therefore makes it imperative to go beyond justice requirements in the design.

A third argument, also based on bounded rationality, has to do with the possibility of learning, i.e., the fact that in any management control interaction between any two people, both of them may change their minds about the desirability of some anticipated state of affairs. Power needs to be delegated in the expectation that people will honor the trust placed in them by exercising power correctly (Simons, 1995b). Flexibility has been considered important in order to decrease uncertainty (Chapman, 1998). This informal dimension, which we identify with the use that is made of the MCS, has been treated as a behavioral dimension in the MCS literature, by accepting enabling uses of MCS (Ahrens and Chapman, 2004) and the use of interactive systems to foster other desirable variables that may have some impact on interest alignment (Bisbe and Malagueño, 2009; Simons, 1995b).

It is not enough, therefore, for a MCS to include a set of justice requirements in its design. A MCS always requires informal procedures, which by their very nature include some form of subjectivity. In our analysis, that subjectivity has to do with the fairness shown by the users of the system. 
Research into this issue, applied to MCS, has been mainly empirical (Cugueró-Escofet and Rosanas, 2011), studying different organizational justice dimensions and their role in different hypothesized realities (see as examples Bol et al., 2010; Seifert et al., 2010; Sholihin and Pike, 2009; Yue, 2008). One attempt to link constructs used in the organizational justice literature and import them into behavioral accounting is that of Burney et al. (2009), who use two of the four components of the organizational justice measure provided in Colquitt (2001) and find that some aspects relevant to management control systems are best captured by distributive and procedural justice. This is a valuable finding regarding justice perceptions and MCS use, but some of the informal aspects of justice in the way MCS are used remain unexplored, as they are not found to be important in Burney et al.'s study. Those informal aspects need to be prescribed and will be included in our analysis. Justice and fairness in the way MCS are used has in part been studied empirically in the form of interactional justice. Interactional justice is individuals' justice perceptions regarding whether managers use procedures to deliver outcomes and information fairly (Bies, 1987a; Bies and Moag, 1986; Bies, 1987b). In summary,

Proposition 6a: Just use of a MCS should include willingness on the part of managers to use the just system and to care for fairness in the results.

Proposition 6b: Just use of a MCS should include willingness on the part of managers to propose changes to the MCS design that will make it more just.

The problem of subjectivity is that of arbitrariness (Posthuma and Dworkin, 2000). Even if a MCS design meets the justice requirements, decision makers, when using the system, may interpret certain specific arrangements in very atypical situations differently. More importantly, we know that once a MCS has established a basic equality, because equality is not possible in all facets, inequalities appear and are necessary when using the system (Sen, 1992). It is unjust and unfair for people who are not behaving in the same way to receive the same treatment in all MCS arrangements, even if they are in an equal position and have the same behavior options. That said, to prevent inequalities from seeming arbitrary, the reasons for them must be explained. In summary,

Proposition 7: A just use of a MCS should make explicit and explain specific inequalities in any reward or recognition, basing them on well argued criteria, so as to avoid arbitrariness.

\section{A dynamic analysis of MCS based on formal and informal justice}

We have shown that any governance system needs to include aspects of justice in order to be considered a means to attain a well ordered cooperation for people (Aristotle, 2000). Most research has set out to show empirically how fair or unfair certain outcomes, procedures and interactions using MCS are perceived to be (Cugueró-Escofet and Rosanas, 2011). Very little research has analyzed the concepts of formal and informal justice in conjunction in the MCS literature (Arnett, 1967; Luft, 1997; Pallot, 1991; Williams, 1987). On the one hand, a MCS design can be formally just or formally unjust, and the use of the MCS can be informally just or informally unjust. This is shown as a $2 \times 2$ matrix in Table 1 .

A just design of a MCS combined with just use of the MCS leads to what we call maximum goal congruence; an unjust design combined with just use, to occasional goal congruence; a just design combined with unjust use, to perverse goal congruence; and an unjust design combined 
with unjust use, to minimum goal congruence. In what follows we shall expand on these four types of goal congruence and briefly indicate the plausible dynamics of the four situations.

Another aspect we want to address is how our table can be accommodated to the mainstream contingency approach to MCS design and use, which considers MCS design and use to be context-dependent (Chenhall, 2003). According to the contingency literature, some MCS characteristics are contingent on relevant contextual variables; and we cannot avoid considering justice as being contingent on external situations. For this reason we need to show how this is addressed in our archetypical matrix. We think that for a given company, in a given situation and for some specific type of MCS, the four types of goal congruence exist when combining (in)justice of MCS design and use. But these four types of goal congruence are not absolute states; the absolute aspect is the comparison between each of the four types of goal congruence. We always find a cell (combining formal and informal justice) in which the maximum possible level of goal congruence, contingent to that specific situation, is achieved, and the same for the other three possibilities. If the external situation changes, our matrix will not be the same in absolute terms; but the four types of goal congruence will still be comparable with one another, and the combination of formal and informal justice will lead to the maximum possible goal congruence contingent to that specific situation. Our matrix will be more or less stressed in terms of absolute level of goal congruence, depending on external factors, but it will still be useful in terms of comparisons between the four types of goal congruence and their archetypical characteristics.

\section{Table 1}

Combinations of justice of the design and use of the MCS

\begin{tabular}{|l|l|l|l|}
\cline { 3 - 4 } \multicolumn{2}{c|}{} & \multicolumn{2}{c|}{ MCS design } \\
\cline { 2 - 4 } \multicolumn{2}{c|}{} & \multicolumn{1}{c|}{ Formally Just } & \multicolumn{1}{c|}{ Formally Unjust } \\
\hline \multirow{2}{*}{ MCS use } & Informally Just & Maximum goal congruence & Occasional goal congruence \\
\cline { 2 - 4 } & Informally Unjust & Perverse goal congruence & Minimum goal congruence \\
\hline
\end{tabular}

\subsection{Maximum goal congruence}

When a just design of a MCS is used justly, there is formal and informal justice, and the alignment of individuals and organization may be at its maximum for that specific situation. Justice requirements are included in the design, and managers use them proactively and consistently, balancing individual circumstances and attempting to check in every decision whether the system design makes sense in terms of justice.

This is because individual organizational members are required to perform in a way that is consistent with their achievements and using variables they can influence (Leventhal et al., 1980; Van den Bos et al., 1996). They are in an organization that sets a minimum level of compensation and does not create huge differences between peers (Hambrick, 1987; Siegel and Hambrick, 2005), and that provides formal mechanisms to repair injustices and change the system when necessary (Conlon et al., 2005; Cropanzano et al., 2007; 0'Malley and Greenberg, 1983; Wenzel et al., 2008). Managers' actions are consistent with the system and the decisions they make using the system include a degree of flexibility and balance (Aristotle, 2000; Bies, 1987a; Bies and Moag, 1986; Bies, 1987b; Posthuma and Dworkin, 2000). In this type of 
situation we have a proactive model in which managers use the system consistently, and we can expect the achievement of substantial fairness in the results. The probability that fairness is present in the results is large. When fairness is not present, people can ask the manager, who, being informally just, may consider changing certain aspects of the system, or of the way it is used which, though considered formally and informally just in the past, now need to be accommodated to the current situation. And when justice is present in the design and decisions, people are motivated to make the greatest possible effort to cooperate with peers and managers to attain organizational goals, as they see their goals as part of a greater goal (Simon, 1964), to be achieved through the joint effort of the whole organization. Goal congruence thus reaches a contingent maximum. At the same time, when people cooperate and their objectives are aligned, there is also greater fairness in the consequences or results;and if people do not perceive such fairness, they can appeal to the manager's informal justice. In terms of levers of control, and looking at belief, boundary, diagnostic and interactive systems, the justice aspects of design are consistent with their managerial use in terms of justice (Simons, 1994). People in these organizations will commit, as committing to the organization benefits them as members of the organization. In summary,

Proposition 8: A just design and use of the formal MCS will lead to maximum goal congruence and a maximum degree of identification by members with the organization (that is to say, the maximum that is possible under the organizational circumstances).

This situation would presumably be reasonably stable, as there are no circumstances in the organization that could motivate individuals to dissent. If individuals were to dissent (because they perceived some unfairness in the results), justice mechanisms and just managers would deal with the situation in a consistent way to find a solution. There is consistency between the system design and the way it is used. Generally speaking, injustices scarcely appear in this kind of system; and if they do, they are easily repaired through built-in provisions, justly applied by the system manager.

\subsection{Occasional goal congruence}

After analyzing the state of maximum goal congruence, we move towards a more common state, one in which many organizations find themselves, where goal congruence is occasional and the system does not have a perfectly just design but nevertheless has informal justice. This type of situation rewards in-depth study, especially of the dynamics it can generate with respect to learning and future development from the starting situation that lead to better MCS goal congruence. Our purpose here is to show that this archetype of goal congruence will exist if MCS design and use are just.

Empirical evidence has shown that managers acting justly may be willing to find ways to repair injustices (Cropanzano et al., 2007). Evaluative learning takes place: after first subjectively repairing injustices, managers may start to propose changes to the parts of the system that have generated unfair consequences (Aristotle, 2000). Acts that will change the system need a measure of goodwill on the part of those in power. Prescriptive research has considered that the virtue of justice is essential when people are able to decide about the recognition others should receive (Aristotle, 2000; Folger and Cropanzano, 2001). Empirical studies suggest that people care about the nature of their interactions with others and judge those interactions in terms of how just they perceive them to be (Bies and Moag, 1986; Bies, 1986). Empirically, the source of an injustice has been regarded as the central actor against whom reactions to the injustice are directed once the injustice has been perceived (Lavelle et al., 2007). In summary, 
Proposition 9a: An unjust design of a MCS used justly allows for occasional goal congruence. A just use of such a system leads to positive learning, which can repair unfairnesses and promote changes to the MCS design to make if more just.

This situation is highly unstable and evolves towards a better version of itself, tending towards maximum goal congruence, as informal justice transforms the system from an unjust design into a just design.

Usually, therefore, this state will not last long, as managers' willingness to use the system with justice makes them strive to change the system and so make it just in terms of design. Managers may become aware that something is wrong in the system when they themselves look at the unfairnesses the system creates; or alternatively, when people in the organization complain about perceived unfair results. An informally just manager will be alert to the possibility of unfairness, and will investigate any complaints of unfairness. The literature on virtuous circles can provide some clues as to how this situation evolves over time: learning leads to a deviation-amplifying process that results in an improvement of the situation, making future states of affairs steadily fairer compared to previous ones (Ashton, 1976; Maruyama, 1963; Weick, 1979; Wender, 1968). Maruyama concludes that in systems in which two variables are interdependent, there can be deviating effects that amplify both variables. Thus, when one variable increases, the other increases and vice versa, until they eventually reach a stable state of equilibrium or else increase continuously over time.

In our case, informal justice increases the formal fairness of the system, so that the future justice of the system is amplified, as is the future justice of the decision maker. As a result, the unjust design of the MCS may be transformed into a more just one, eventually leading to a situation of maximum goal congruence. In summary,

Proposition 9b: In a situation of occasional goal incongruence, managers acting justly can transform the system into a formally just one by changing the parts of the system that have proven formally unjust. Ultimately, this can lead to a situation of maximum goal congruence.

Let us illustrate the situation with an example. Imagine an organization that is starting its activities. Typically, the MCS will be rudimentary and incomplete, and so will be its design in terms of justice requirements. At this stage, the MCS may be designed to assign bonuses in a way that works for the sales department but offers no incentive to people in other departments that should be supporting the sales force. If managers use the system justly, they can do two things. Either they can adopt reparation policies in the short run, adjusting the bonuses for the support people; or they can work to bring about changes in the incentive schemes, so that people in the support departments are evaluated and rewarded based on the support they actually provide. Informal justice in the use of the system may thus end up improving the MCS design. 


\subsection{Perverse goal congruence}

When a MCS design is just and the system is used unjustly, there will be room for dysfunctional learning. Dysfunctional learning will occur because in order to remedy unfairness arising from the unjust use of the system, people will demand changes in the system itself and call for the establishment of stricter rules that are harder to adhere to, as suggested in Merton's control model (Hopwood, 1974; March and Simon, 1993). This can have consequences that run counter to just design requirements and in the end will result in a loss of goal congruence. These initial proposals for increasing formal justice may start with the legitimate aim of assuring fairness in how employees are treated. But if they are exacerbated, they can end up creating even greater unfairness (Sitkin and Bies, 1993). Creating new rules may be legitimate, insofar as it is the accepted way of dealing with perceived unfairness of results. In order to be dynamic, accommodate new demands, and avoid future unfairness, the system must be ready to include new rules. Problems arise, however, when new rules are included in the MCS without any logic (in contrast to the process that Bies and Tyler call 'legal induction') and rules are adopted without proper consideration of existing rules, as occurs in the process that Bies and Tyler call 'legalization'. The legalization process is not aimed at improving the MCS; instead it is liable to break the chain of command and disintegrate the decision-making process itself (Sitkin and Bies, 1993, p. 345).

Empirical research has shown that when people suffer an unfairness, their first reaction is to blame the MCS design (Cropanzano and Byrne, 2001). This can lead to changes in the MCS, aimed at preventing future unfairness. As a result, the system becomes more rigid and loses its flexibility. As the complexity of the system increases, it tends to generate distrust, leading to the institutionalization of adversarial relationships (Cropanzano and Byrne, 2001, p.34). Highly formalized systems also tend to include too many rules, which are likely to contradict one another and are harder to adhere to. Furthermore, if those rules are created through 'legalization', with no intention of developing a better decision-making process, the unfairness is not ameliorated and new unfairnesses are likely to appear in future decisions. As a result, the 'legalization' process may spread through the organization, so that managers would start to legitimate themselves by adhering only to the rules that are perceived as being just, without any real intention of including those that improve the formal justice of the MCS. In fact, most of the rules incorporated may worsen the actual justice of the MCS (Sitkin and Bies, 1993).

Another consequence is the dysfunctional learning that takes place in managers. Through using the system unjustly, unjust managers learn how to "cheat" the system every time a new just rule is introduced. They become better and better at doing this until, in the end, they fully master being unjust (Aristotle, 2000). In these two cases, injustices are unlikely to be repaired, as people either call for more rules or, in the case of managers, learn how to be more unjust by defeating the system and any new rules. In summary,

Proposition 10a: Unjust use of a MCS designed following justice requirements will create perverse goal congruence. Emphasis on rules will make the MCS more unjust in terms of design, while decision makers will become increasingly more unjust as they learn how to circumvent the system. 
Both types of dysfunctional learning - by managers and by people calling for more rules - can transform a MCS designed following just criteria into a formally unjust MCS and lead to minimum goal congruence and so to lower levels of identification by individuals with the organization.

This situation will become unstable and will tend to deteriorate, as learning does not increase in the right direction. Injustices are not repaired (even if the MCS design includes repair mechanisms) and the MCS will not change for the better (e.g., through replacement of unjust rules, rather than through a mere increase in the number of rules) (Cropanzano et al., 2007). The use of the MCS made by an unjust manager typically leaves room for enough excuses to explain its misuse (Aristotle, 2000).

We have already explored the possible role of deviation-amplifying processes in the situation of occasional goal congruence. In this case, the effect of the amplification is negative, as the starting point is the unjust use of a formally just MCS (Ashton, 1976; Maruyama, 1963; Weick, 1979; Wender, 1968). Maruyama concludes that in systems in which two variables are interdependent, there can be deviating effects that amplify both variables. Thus, when one variable decreases, the other decreases as well, and so on in turn until, in the end, they either reach a stable state of equilibrium or decrease continuously over time. In our case, it is clear that informal justice reduces the formal justice of the system, which in turn reduces the informal justice, until the situation becomes one of minimum goal congruence.

This type of deviation-amplifying effect has already been explored in relation to the unintended effects of MCS (Ashton, 1976). Ashton considers that MCS can create intended or unintended functional or dysfunctional consequences. Where the consequences are unintended and dysfunctional, MCS end up breaking down, precisely because of the deviation-amplifying effects of those unintended, dysfunctional consequences that we have mentioned (Ashton, 1976, p.290).

Applied to our case, empirical evidence suggest that where there is informal injustice in the use of a system and people perceive such injustice, they usually demand greater formal justice (Cropanzano and Byrne, 2001). Demanding more justice in MCS design has the unintended, dysfunctional effect of increasing informal injustice in the use of the system and injustice in the system design (Cropanzano and Byrne, 2001). Finally, unjust MCS design and unjust use of the MCS drive a loop of mutual deviation-amplifying effects that makes both types of injustice increase steadily over time.

This learning process of injustice is highly dynamic and has no clear end situation, although we can imagine that it will end with the destruction of unity inside the organization. Empirical evidence suggest that people who are on the receiving end of unjust decisions through unjust systems will behave accordingly towards the organization, losing commitment and gaining motivations that work against organizational interest alignment or goal congruence (Gottschalg and Zollo, 2007).

Another possible consequence that leads to destruction is the failure to develop core competences, as people do not receive what they deserve in return for the contributions they make (Alexander et al., 1995). People will quit for more favorable organizations that show more consistency between management control design and use. In summary, 
Proposition 10b: Perverse goal congruence will tend towards minimum goal congruence and people will identify less and less with the organization, because no attempt is made to effectively solve the unfairness.

Examples of perverse goal congruence can be seen in successions, mainly when they take place suddenly in a top position in an organization. The selection process may have been justly designed, but there can be no assurance that the new holder of the position will be just in her actions. Generally speaking, when recruiting processes take place under time pressure, it will be difficult to assess the degree of real informal justice that people will show later on. At the time of recruiting, people tend to talk about justice in theoretical terms; but it is impossible to guarantee that decisions will be taken fairly when the system is used in the future.

In these situations, the fact that a new top manager may use the system unjustly may not be a real problem in the short run; but it can become problematic over time, as small shifts in the use of the system can turn what was a justly designed MCS into unjust one. This often goes unnoticed until real damage has been done, by which time the situation is difficult to reverse.

\subsection{Minimum goal congruence}

When a MCS design is unjust and the system is used unjustly, there will be a situation of minimum goal congruence and organizational members will not identify with the organization at all. We have already explained the consequences of organizational injustice. According to empirical studies, perceptions of injustice have adverse organizational consequences (see e.g. Colquitt et al., 2001; Greenberg, 1990c) and need to be managed through systems and managers (Cropanzano et al., 2007). Those consequences may end up destroying value, because people tend to engage in behaviors that are intended to damage the organization (Brockner and Greenberg, 1990; Greenberg, 1990b). In the end, the motivations of the organization and its members become misaligned, as there are motivations to create such a misalignment (Gottschalg and Zollo, 2007).

Proposition 11: A MCS designed with unjust criteria and used unjustly leads to minimum goal congruence.

This situation corresponds to a somewhat stable state of equilibrium, as individuals have no motivation to work for the organization. Negative learning drives the organization toward a more extreme situation of injustice (Maruyama, 1963). There is consistency between the system and the way it is used. Every time the MCS is used, the organization deteriorates. The organization becomes overall an unjust place to work and people either plan to leave the organization or else try to survive inside it by isolating themselves from their surroundings.

The consequences of what we have explained above are very important for the MCS literature. When a situation of injustice appears, people tend to put the emphasis on system design and call for the introduction of new rules to improve justice perceptions (Cropanzano and Byrne, 2001). Of course, a just MCS design is important, but how people use the system is even more important, as the willingness to be just is more powerful than a perfectly justly designed MCS, and people are motivated to engage in behavior that can improve the current state of affairs (Finnis, 1980). 
The emphasis should be on informal justice in the use of the system. Justice when using a MCS will allow for corrections to the MCS, where there is scope for improvement. Also, where there are too many rules, justice may suggest that certain rules be omitted, so as to keep the system simple. The subjective element that informal justice introduces into the system is thus crucial and essential to achieving stable goal congruence and full identification with the organization on the part of organizational members, both of which are core objectives of management control systems.

Putting the emphasis on justice in the use of the system can result in generally more just organizations and greater goal congruence (Cropanzano et al., 2007; Cropanzano and Byrne, 2001). If the emphasis is on justice in MCS design while justice in MCS use is omitted, the organization is likely to end in a situation of minimum goal congruence, which is very difficult to turn back into goal congruence. For this reason we have a final proposition:

Proposition 12: To achieve greater goal congruence and closer identification with the organization on the part of organizational members, emphasis must be placed on using the system more justly rather than on making the actual system design more just. If the system is used justly, it will eventually become more just in its design.

\section{Conclusions}

To conclude, attempts have been made in MCS research to empirically show the importance of fairness. However, there is no theoretical work that deals in depth with the prescriptive role of justice in MCS design and MCS use.

We have shown that every MCS has both design features and informal processes of use, or ways in which it can be managed. MCS management is subjective, as it involves managers' making decisions and acting in relation to outcomes and procedures when the system is applied in a specific context. Justice requirements therefore need to be linked both to the design of a MCS and to subjective uses of the MCS. In our analysis we consider managerial action and MCS design in combination and shows which combination of the two is conducive to a maximum level of goal congruence over time.

We have made an effort to bring together the literature on MCS, the recent literature on justice, prescriptive models and empirical evidence, and we have listed the requirements of a just MCS design and fair use of the MCS. This allows us to finally give a specific role to informal aspects of MCS use that previously have been studied in terms of users' motives, but not in terms of the consequences they may have for goal congruence. Our work provides a theoretical grounding for future research, which is a necessary step before any progress can be made in this important stream of research into the role of justice in MCS.

Furthermore, we have developed a model of goal congruence types, as an effect of the justice of the system's design and use. This leaves us with a range of possible goal congruence situations that lead to different learning dynamics over time. Occasional goal congruence deserves a special mention. When it happens, positive evaluative learning takes place and managers strive to be just, subjectively seeking immediate solutions to repair the unfairness caused by an unjustly designed MCS. In the end, the system itself improves in terms of justice design. This learning increases managers' justice and eventually transforms the situation into one of maximum goal congruence. 
For this reason, we argue that subjective aspects of justice, manifested in the way the system is used, are capable of improving the organization and increasing people's identification with the organization's mission and their commitment to its goals. Over time, this leads to greater goal congruence. We think that our model allows a deeper understanding of why justice is important and why subjectivity is unavoidable, making the notion of a perfect mechanical design that needs no people and creates a stable situation of goal congruence unrealistic. In contrast, having people who are trained and willing to be fair is a starting point for creating better control systems and better organizations.

We need to be cautious in dealing with intermediate situations that depart from our stereotyped four states. We have mentioned that systems can be partially just in terms of design. This can mean departing from our ideal situations. At the same time, we can have different levels of informal justice. For the same level of actual justice of the design, depending on the level of informal fairness, goal congruence can improve more or less quickly. Further research is needed to consider the differing capacity of different aspects of informal justice to improve formal systems, thus creating better goal congruence. We also need to increase our knowledge through empirical research that examines whether and to what extent these states and dynamics actually exist. Such future research will also help to refine the model and provide a clearer understanding of intermediate situations of formal fairness. However, we believe that the conceptual clarification that this paper provides is a necessary step before undertaking such empirical research. 


\section{References}

Abernethy, Margaret A. and Peter Brownell (1997), Management Control Systems in Research and Development Organizations: The Role of Accounting, Behavior and Personnel Controls, Accounting, Organizations and Society, 22 (3/4), pp. 233-248.

Abernethy, Margaret A. and Peter Brownell (1999), The role of budgets in organizations facing strategic change: an exploratory study, Accounting, Organizations and Society, 24 (3), pp. 189-204.

Adams, Darrel K., O. J. Harvey, and Richard E. Heslin (1966), Variation in flexibility and creativity as a function of hypnotically induced past histories, In: O. J. Harvey (Ed.), Experience, structure and adaptability, New York: Springer, pp. 217-234.

Adams, J. S. and S. Freedman (1976), Equity revisited: comments and annotated bibliography, In: L. Berkowitz and L. Walster (Eds.), Advances in Experimental Social Psychology, Academic Press, New York, pp. 43-90.

Adams, J. S. (1963), Toward an understanding of inequity, Journal of Abnormal and Social Psychology, 67, pp. 422-436.

Adams, J. S. (1965), Inequity in social exchange. In: L. Berkowitz (Ed.), Advances in experimental social psychology, New York: Academic Press, pp. 267-299.

Adler, Paul S. and Bryan Borys (1996), Two Types of Bureaucracy: Enabling and Coercive, Administrative Science Quarterly, 41, pp. 61-89.

Ahrens, T. and C. S. Chapman (2004), Accounting for flexibility and efficiency: a field study of management control systems in a restaurant chain, Contemporary Accounting Research, 212, pp. 271-301.

Alexander, S., R. R. Sinclair and L. E. Tetrick (1995), The role of organizational justice in defining and maintaining the employment relationship, In: L. E. Tetrick and J. Barling (Eds.), Changing employment relations: Behavioral and social perspectives, American Psychological Association, Washington, DC, pp. 61-89.

Anthony, Robert N. and Vijay Govindarajan (2003), Management Control Systems, Mc Graw Hill. Aquinas, Thomas (2002), On Law, Morality and Politics, Hackett Publishing Company, Inc.

Argyris, C. (1953), The Impact of Budgets on People, The Controllership Foundation, New York.

Aristotle (2000), Nicomachean Ethics, The Internet Classics Archive by Daniel C. Stevenson.

Arnett, Harold E. (1967), The Concept of Fairness, Accounting Review, 42 (2), p. 291.

Ashford, S. J., and G. B. Northcraft (1992), Conveying more (or less) than we realize: The role of impression-management in feedback-seeking, Organizational Behavior and Human Decision Processes, 53, pp. 310-334.

Ashton, Robert H. (1976), Deviation-amplifying feedback and unintended consequences of management accounting systems, Accounting, Organizations and Society, 1 (4), pp. 289-300.

Barnard, Chester I. (1938), The functions of the executive, Harvard University Press, Cambridge, MA. Bentham, J. (1948), An Introduction to the Principles of Morals and Legislation, Hafner, New York. 
Bies, R. J. (1987a), Beyond 'voice': the influence of decision-maker justification and sincerity on procedural fairness judgments, Representative Research in Social Psychology, 17 (1), pp. 3-14.

Bies, R. J. and J. Moag (1986), Interactional justice: communication criteria of fairness, In: R. Lewicki, B. Sheppard and M. Bazerman (Eds.), Research on Negotiation in Organizations, Greenwich: JAI Press, pp. 43-55.

Bies, Robert J. (1986), Identifying principles of interactional justice: The case of corporate recruiting, In: Robert J. (Chair) Bies (Ed.), Moving beyond equity theory: New directions in research on justice in organizations, Symposium at the Annual Meeting of the Academy of Management, Chicago IL.

Bies, Robert J. (1987b), The predicament of injustice: The management of moral outrage, In: L. L. Cummings and B. M. Staw (Eds.), Research in Organizational Behavior, JAI, Greenwich, CT, pp. 289-319.

Bisbe, J. and R. Malagueño (2009), The choice of Interactive Control Systems under Different Innovation Management Modes, European Accounting Review, 18 (2), pp. 371-405.

Bisbe, J. and D. Otley (2004), The effects of interactive use of management control systems on product innovation, Accounting, Organizations and Society, 32 (7-8), pp. 789-820.

Blader, S. and R. Tyler (2003), A four-component model of procedural justice: Defining the meaning of a "fair" process, Personality and Social Psychology Bulletin (29), pp. 747-758.

Bol, Jasmijn C., Timothy M. Keune, Ella Mae Matsumura and Shin Jae Yong (2010), Supervisor Discretion in Target Setting: An Empirical Investigation, Accounting Review, American Accounting Association, pp. 1861-1886.

Brockner, J. and J. Greenberg (1990), The impact of layoffs on survivors: An organizational justice perspective, Applied social psychology and organizational settings, pp. 45-75.

Burney, Laurie L., Christine A. Henle, and Sally K. Widener (2009), A path model examining the relations among strategic performance measurement system characteristics, organizational justice, and extra- and in-role performance, Accounting, Organizations and Society (34), pp. 305-321.

Burrell, G. and G. Morgan (1979), Sociological Paradigms and Organisational Analysis, Heinemann, London.

Chapman, Christopher S. (1998), Accountants in Organizational Networks, Accounting, Organizations and Society, 23 (8), pp. 737-766.

Chenhall, Robert H. (1986), Authoritarianism and Participative Budgeting: A Dyadic Analysis, Accounting Review, 61 (2), pp. 263-272.

Chenhall, Robert H. (2003), Management control systems design within its organizational context: findings from contingency-based research and directions for the future, Accounting, Organizations and Society, 28 (2/3), pp. 127-168.

Chenhall, Robert H. and Peter Brownell (1988), The Effect of Participative Budgeting on Job Satisfaction and Performance: Role Ambiguity As An Intervening Variable, Accounting, Organizations and Society, 13 (3), pp. 225-233. 
Chomsky, N. and M. Foucault (1974), Human Nature: Justice versus Power, In: F. Elders (Ed.), Reflexive Water: The Basic Concerns of Mankind, Souvenir, London.

Cohen, R. L. and J. Greenberg (1982), The justice concept in social psychology, In: J. Greenberg and R. L. Cohen (Eds.), Equity and Justice in Social Behavior, Academic Press, New York, pp. 1-41.

Coletti, Angela L., Karen L. Sedatole and Kristy L. Towry (2005), The Effect of Control Systems on Trust and Cooperation in Collaborative Environments, Accounting Review. American Accounting Association, pp. 477-500.

Colquitt, J. A., J. Greenberg and B. A. Scott (2005a), Organizational Justice: where do we stand? In: J. Greenberg and J. A. Colquitt (Eds.), Handbook of Organizational Justice, Mahwah, NJ: Lawrence Erlbaum, pp. 589-619.

Colquitt, J. A., J. Greenberg and C. P. Zapata-Phelan (2005b), What is organizational justice? A historical overview, In: J. Greenberg and J. A. Colquitt (Eds.), Handbook of Organizational Justice, Mahwah, N. J: Lawrence Erlbaum.

Colquitt, Jason A. (2001), On the Dimensionality of Organizational Justice: A Construct Validation of a Measure, Journal of Applied Psychology, 86 (3), pp. 386-400.

Colquitt, Jason A., D. E. Conlon, M. J. Wesson, C. O. Porter and K. Y. Ng (2001), Justice at the millennium: A meta-analytic review of 25 years of organizational justice research, Journal of Applied Psychology, 86 (3), pp. 425-445.

Conlon, Donald E., C. J. Meyer and Jaclyn M. Nowakowski (2005), How does Organizational Justice affect performance, withdrawal and counterproductive behavior? In: J. Greenberg and J. A. Colquitt (Eds.), Handbook of Organizational Justice, Nahwah, NJ: Lawrence Erlbaum.

Cropanzano, R., David E. Bowen and Stephen W. Gilliland (2007), The Management of Organizational Justice, Academy of Management Perspectives, 21 (4), pp. 34-48.

Cropanzano, R. and R. Folger (1989), Referent Cognitions and task decision autonomy: beyond equity theory, Journal of Applied Psychology, 74, pp. 293-299.

Cropanzano, R., Barry Goldman and R. Folger (2005), Self-interest: defining and understanding a human motive, Journal of Organizational Behavior, 26, pp. 985-991.

Cropanzano, R., Deborah E. Rupp, Mohler ? and M. Schminke (2001), Three Roads to Organizational Justice, In: G. R. Ferris (Ed.), Research in Personnel and Human Resource Management, Elsevier Science, New York, pp. 1-113.

Cropanzano, Russell (Ed.), (1993), Justice in the Workplace: Approaching Fairness in Human Resource Management, Lawrence Erlbaum, Hillsdale, NJ.

Cropanzano, Russell (Ed.), (2001), Justice in the Workplace: From Theory to Practice, Lawrence Erlbaum, Mahwah, NJ.

Cropanzano, Russell and Maureen L. Ambrose (2001), Procedural and Distributive Justice Are More Similar than You Think: A Monistic Perspective and a Research Agenda, In: Jerald Greenberg and Russell Cropanzano (Eds.), Advances in Organizational Justice, Stanford University Press, Stanford, California, pp. 119-151. 
Cropanzano, Russell and Zinta S. Byrne (2001), When it's time to stop writing policies. An inquiry into procedural justice, Human Resource Management Review, 11, pp. 31-54.

Cugueró-Escofet, Natàlia and Josep Maria Rosanas (2011), Research on Management Control Systems, Fairness and Justice: an analytical review, Working paper, IESE Business School.

Davila, Antonio and George Foster (2007), Management Control Systems in Early-Stage Startup Companies, Accounting Review, 82 (4), pp. 907-937.

Davila, Antonio, George Foster and Mu Li (2009), Reasons for management control systems adoption: Insights from product development systems choice by early-stage entrepreneurial companies, Accounting, Organizations and Society, 34 (3/4), pp. 322-347.

Davila, T. (2005), An exploratory study on the emergence of management control systems: formalizing human resources in small growing firms, Accounting, Organizations and Society (30), pp. 223-248.

Davila, Tony (2000), An empirical study on the drivers of management control systems' design in new product development, Accounting, Organizations and Society, 25 (4/5), pp. 383-409.

Demski, Joel S. (1976), Uncertainty and Evaluation Based on Controllable Performance, Journal of Accounting Research, 14 (2), pp. 230-245.

Derrida, J. (1995), The Gift of Death, University of Chicago Press, Chicago.

Derrida, J. (1997), Politics of Friendship, Verso, New York.

Epstein, M. and J. F. Manzoni (1997), The balanced scorecard and tableau du bord:translating strategy into action, Management Accounting, 79 (2), pp. 28-36.

Finnis, J. (1980), Natural Law and Natural Rights, Clarendon Press, Oxford.

Flamholtz, Eric G., T. K. Das and Anne S. Tsui (1985), Towards an Integrative Framework of Organizational Control, Accounting, Organizations and Society, pp. 35-50.

Flyvbjerg, B. (1998), Habermas and Foulcault: thinkers for civil society? Bristish Journal of Sociology, 49 (2), pp. 210-233.

Folger, R. (1986), Rethinking equity theory: A referent cognitions model, In: H. W. Beirhoff, R. L. Cohen and J. Greenberg (Eds.), Justice in Social Relations, New York: Plenum Press, pp. 145-162.

Folger, R. (1998), Fairness as a moral virtue, In: M. Schminke (Ed.), Managerial Ethics: Moral Management of People and Processes, Mahwah, NJ: Lawrence Erlbaum.

Folger, R. and R. Cropanzano (1998), Organizational Justice and human resource management. Beverly Hills, CA: Sage.

Folger, R. and R. Cropanzano (2001), Fairness theory: justice as accountability, In: J. Greenberg and R. Cropanzano (Eds.), Advances in Organizational Justice, Stanford, CA: Stanford University Press, pp. 1-55.

Fortin, Marion (2008), Perspectives on organizational justice: Concept clarification, social context integration, time and links with morality, International Journal of Management Reviews, 10 (2), pp. 93-126. 
Foucault, M. (1988), The Ethic of Care for the Self as a Practice of Freedom, In: J. Bernauer and D. Rasmussen (Eds.), The Final Foucault. MIT Press, Cambridge, Mass.

Fredrickson, James W., Alison Davis-Blake and W. M. Gerard Sanders (2010), Sharing the wealth: social comparisons and pay dispersion in the CEO's top team, Strategic Management Journal, 31 (10), pp. 1031-1053.

Gauthier, David (1986), Morals by agreement, Oxford University Press, Oxford.

Gilliland, S. W. and D. Chan (2001) Justice in organizations: Theory, methods and applications, In: N. Anderson, D. S. Ones, H. K. Sinangil and C. Viswesvaran (Eds.), Handbook of Industrial, Work and Organizational Psychology: Volume 2 Organizational Psychology, Sage, Thousand Oaks, CA, pp. 143-165.

Giraud, Françoise, Pascal Langevin and Carla Mendoza (2008), Justice as a rationale for the controllability principle: A study of managers' opinions, Management Accounting Research, 19 (1), pp. 32-44.

Goodman, Paul S. and Abraham Friedman (1971), An Examination of Adams' Theory of Inequity, Administrative Science Quarterly, 16 (3), p. 271.

Gottschalg, Oliver and Mauricio Zollo (2007), Interest alignment and competitive advantage, Academy of Management Review, 32 (2), pp. 418-437.

Gouldner, A. W. (1954), Patterns of Industrial Bureaucracy, Free Press, Glencoe Illinois.

Greenberg, J. (1990a), Looking fair vs. being fair: Managing impressions of organizational justice, Research in Organizational Behavior, 12, pp. 111-157.

Greenberg, J. (1990b), Employee theft as a reaction to underpayment inequity: The hidden cost of pay cuts, Journal of Applied Psychology, 75, pp. 561-568.

Greenberg, J. (1990c), Organizational justice: Yesterday, today, and tomorrow, Journal of Management, pp. 399-432.

Greenberg, J., Robert J. Bies and D. E. Eskew (1991), Establishing fairness in the eye of the beholder: Managing impressions of organizational justice, In: R. Giacalone and P. Rosenfeld (Eds.), Applied impression management: How image making affects managerial decisions, Sage, Newbury Park, CA, pp. 111-132.

Greenberg, Jerald (1987), A Taxonomy of Organizational Justice Theories, The Academy of Management Review, 12 (1), pp. 9-22.

Greenberg, Jerald (1988), Using social accounts to manage impressions of performance appraisal fairness, Annual meeting of the Academy of Management, Anaheim, CA.

Greenberg, Jerald and Robert J. Bies (1992), Establishing the Role of Empirical Studies of Organizational Justice in Philosophical Inquiries into Business Ethics, Journal of Business Ethics, 11 (5/6), pp. 433-444.

Habermas, J. (1987), The Philosophical discourse of Modernity, MIT Press, Cambridge: Mass.

Habermas, J. (1990), Moral Consciousness and Communicative Action, MIT Press, Cambridge, Mass. 
Hambrick, Donald C. and Sydney Finkelstein (1987), Managerial discretion: A bridge between polar views of organizational outcomes, Research in Organizational Behavior, 9, pp. 369-406.

Hartmann, Frank and Sergeja Slapnicar (2009), How formal performance evaluation affects trust between superior and subordinate managers, Accounting, Organizations and Society, 34 (6-7), pp. 722-737.

Hopper, Trevor and Andrew Powell (1985), Making sense of research into the organizational and social aspects of Management Accounting: a review of its underlying assumptions, Journal of Management Studies, 22 (5), pp. 429-465.

Hopwood, A. G. (1974), Accounting and Human Behaviour, Prentice-Hall, London.

Hurwicz, Leonid (1972), On Informationally Decentralized Systems, In: C. B. McGuire and R. Radner (Ed.), Decision and Organization, North Holland, Amsterdam and London, pp. 297-336.

Johnson, P. and J. Gill (Eds.), (1993), Management control systems and organizational behavior, Chapman Publishing.

Kant, Immanuel (1981), Grounding for the metaphysics of Morals, (Translated by J. W. Ellington), Hackett Publishing Co, Inc.

Kaplan, R. S. and D. Norton (1992), The balanced scorecard: Measures that drive performance, Harvard Business Review, 70, pp. 71-79.

Kaplan, R. S. and D. Norton (1993), Putting the Balanced Scorecard to work, Harvard Business Review, 71, pp. 134-147.

Kaplan, Robert S and David P. Norton (1996), Using the balanced scorecard as a strategic management system, Harvard Business Review (January-February), pp. 75-85.

Kelsen, Hans (1945), General Theory of Law and State. Harvard University Press, Cambridge.

Lavelle, J. J., Deborah E. Rupp and J. Brockner (2007), Taking a Multifoci Approach to the Study of Justice, Social Exchange, and Citizenship Behavior: The Target Similarity Model, Journal of Management, 33 (6), pp. 841-866.

Leventhal, G. S. (1976), The distribution of rewards and resources in groups and organizations, In: L. Berkowitz and E. Walster (Eds.), Advances in Experimental Social Psychology, New York: Academic Press, pp. 91-131.

Leventhal, G. S., J. Karuza and W. R. Fry (1980), Beyond Fairness: A theory of allocation preferences, Justice and social interaction, New York: Springer-Verlag, pp. 167-213.

Libby, Theresa (1999), The influence of voice and explanation on performance in a participative budgeting setting, Accounting, Organizations and Society, 24 (2), pp. 125-137.

Libby, Theresa (2001), Referent Cognitions and Budgetary Fairness: A Research Note. Journal of Management Accounting Research, 13, pp. 91-105.

Lindquist, Tim M. (1995), Fairness as an Antecedent to Participative Budgeting: Examining the Effects of Distributive Justice, Procedural Justice and Referent Cognitions on Satisfaction and Performance, Journal of Management Accounting Research, 7, pp. 122-147.

Locke (1952), The second treatise of Government, Bobbs-Merrill, Indianapolis. 
Long, Chris P., Corinne Bendersky and Calvin Morrill (2011), Fairness Monitoring: Linking Managerial Controls and Fairness Judgments in Organizations, Academy of Management Journal, 54 (5), pp. 1045-1068.

Luft, Joan L. (1997), Fairness, Ethics and the Effect of Management Accounting on Transaction Costs, Journal of Management Accounting Research, American Accounting Association, pp. 199-216.

March, James G. and Herbert A. Simon (1993), Organizations, John Wiley and Sons, Inc.

March, James and Herbert Simon (1958), Organizations, John Wiley and Sons, New York.

Marginson, David E. W. (2002), Management Control systems and their Effects on Strategy Formation at Middle-management levels: Evidence from a U.K. organization, Strategic Management Journal, John Wiley and Sons, Inc., p. 1019.

Maruyama, M. (1963), The second cybernetics. Deviation-Amplifying Mutual Causal Processes, AMerican Scientist, 5 (2), pp. 164-179.

Merchant, Kenneth A. (1985), Budgeting and the propensity to create budgetary slack, Accounting, Organizations and Society, 10 (2), pp. 201-210.

Merton, R. K. (1957), Social Theory and Social Structure, Free Press, Glencoe Illinois.

Milgrom, P. and J. Roberts (1992), Economics, organizations and management, Prentice-Hall International, Inc.

Mundy, Julia (2010), Creating dynamic tensions though a balanced use of management control systems, Accounting, Organizations and Society, 355, 499-523.

O'Malley, M. N. and J. Greenberg (1983), Sex differences in restoring justice: The down payment effect, Journal of Research in personality, 17 (2), pp. 174-185.

Otley, D. T. and A. J. Berry (1980), Control, Organizations and Accounting, Accounting, Organizations and Society, 5 (2), pp. 231-244.

Ouchi, William G. (1979), A Conceptual Framework For The Design Of Organizational Control Mechanisms, Management Science, 25 (9), pp. 833-848.

Pallot, June (1991), The Legitimate Concern With Fairness: A Comment, Accounting, Organizations and Society, pp. 201-208.

Plato (2006), The Republic, (Translated by R. E. Allen), Yale University Press, New Haven.

Posthuma, Richard A. and James B. Dworkin (2000), A Behavioral Theory of Arbitrator Acceptability, International Journal of Conflict Management (1997-2002), 11 (3), p. 249.

Rawls, J. (2003), Justice as Fairness: a restatement, The Belknap press of Harvard University Press.

Rawls, John (1971), A theory of justice, Belknap Press.

Ridgeway, V. F. (1956) Dysfunctional consequences of performance measurements, Administrative Science Quarterly, 1 (3), pp. 240-247. 
Sandel, M. (1984), Liberalism and its Critics, Basil Blackwell, Oxford.

Sandino, T. (2007) 2007. Introducing the First Management Control Systems: Evidence from the Retail Sector, Accounting Review, 82, pp. 265-293.

Scott, John T., Richard E. Matland, Philip A. Michelbach and Brian H. Bornstein (2001), Just Deserts: An Experimental Study of Distributive Justice Norms, American Journal of Political Science, 45 (4), pp. 749-767.

Seifert, Deborah L., John T. Sweeney, Jeff Joireman and John M. Thornton (2010), The influence of organizational justice on accountant whistleblowing, Accounting, Organizations and Society, pp. 707-717.

Selznick, P. (1949), TVA and The Grassroots, Harper Torch Books, New York.

Sen, Amartya (1992), Inequality Reexamined, Harvard University Press.

Shapiro, D. L., E. H. Buttner and B. Barry (1994), Explanations: What factors enhance their perceived adequacy? Organizational Behavior and Human Decision Processes, 58, pp. 346-368.

Shields, Michael D. and S. Mark Young (1993), Antecedents and Consequences of Participative Budgeting: Evidence on the Effects of Asymmetrical Information, Journal of Management Accounting Research, 5, pp. 265-280.

Sholihin, Mahfud and Richard Pike (2009), Fairness in performance evaluation and its behavioural consequences, Accounting and Business Research, Croner.CCH Group Limited, pp. 397-413.

Siegel, Phyllis A. and Donald C. Hambrick (2005), Pay Disparities Within Top Management Groups: Evidence of Harmful Effects on Performance of High-Technology Firms, Organization Science, 16 (3), pp. 259-274.

Simon, H. (1964), On the concept of Organizational Goal, Administrative Science Quarterly, pp. 1-22.

Simons, R. (2000), Performance Measurement and Control Systems for Implementing Strategies, Prentice Hall, Upper Sadle River.

Simons, Robert (1990), The role of management control systems in creating competitive advantage: New perspectives, Accounting, Organizations and Society, 15, pp. 127-143.

Simons, Robert (1994), How new Top Managers Use Control Systems as Levers of Strategic Renewal, Strategic Management Journal, 15 (3), pp. 169-189.

Simons, Robert (1995a), Control in an Age of Empowerment, Harvard Business Review, pp. 80-88.

Simons, Robert (1995b), Levers of Control, Harvard Business School Press, Boston.

Sitkin, S. B. and R. J. Bies (1993), The legalistic organization: definitions, dimensions, and dilemmas, Organization Science, 4 (3), pp. 345-351.

Tannenbaum, A. S. (1968), Control in Organizations, McGraw-Hill, New York. 
Taylor, M. Susan, Suzanne S. Masterson, Monika K. Renard and Kay B. Tracy (1998), Managers' Reactions to Procedurally Just Performance Management Systems, Academy of Management Journal, 41 (5), pp. 568-579.

Taylor, M. Susan, Kay B. Tracy, Monika K. Renard, J. Kline Harrison and Stephen J. Carroll (1995), Due Process in Performance Appraisal: A Quasi-experiment in Procedural Justice, Administrative Science Quarterly, 40 (3), pp. 495-523.

Tedeschi, J. and M. Reiss (1981), Verbal Strategies in Impression Management, In: C. Antaki (Ed.), The psychology of Ordinary Explanations of Social Behavior, Academic Press, London.

Thibaut, J. and L. Walker (1975a), Procedural justice: a Psychological analysis, Hillsdale, NJ: Lawrence Erlbaum Associates.

Thibaut, J. and L. Walker (1975b), Procedural Justice, Erlbaum, Hillsdale, NJ.

Thibaut, John and Walker Laurens (1978), A Theory of Procedure, California Law Review, 66 (3), 541.

Thurston Jr., Paul W. and Laurel McNall (2010), Justice perceptions of performance appraisal practices, Journal of Managerial Psychology, 25 (3), pp. 201-228.

Van den Bos, K., R. Vermunt and H. A. M. Wilke (1996), The consistency rule and the voice effect: the influence of expectations on procedural fairness judgements and performance, European Journal of Social Psychology, 26, pp. 411-428.

Van der Stede, Wim A. (2000), The relationship between two consequences of budgetary controls: budgetary slack creation and managerial short-term orientation, Accounting, Organizations and Society, 25 (6), pp. 609-622.

Vancil, Richard F. (1973), What kind of management control do you need? Harvard Business Review.

Weick, Karl E. (1979), The social psychology of organizing, Random House, New York.

Wender, P. H. (1968), Vicious and Virtuous circles: The role of deviation-amplifying feedback in the origin and perpetuation of behavior, Psychiatry, 31, pp. 309-324.

Wentzel, Kristin (2002), The Influence of Fairness Perceptions and Goal Commitment on Managers' Performance in a Budget Setting, Behavioral Research in Accounting, 14, p. 247.

Wenzel, M., T. G. Okimoto, N. T. Feather and M. J. Platow (2008), Retributive and restorative justice, Law and Human Behavior, 32 (5), pp. 375-389.

Widener, Sally K., (2007), An empirical analysis of the levers of control framework, Accounting, Organizations and Society, 32 (7-8), pp. 757-788.

Williams, Paul F. (1987), The Legitimate Concern with Fairness, Accounting, Organizations and Society, pp. 169-189.

Yue, Zhang (2008), The Effects of Perceived Fairness and Communication on Honesty and Collusion in a Multi-Agent Setting, Accounting Review, American Accounting Association, pp. 1125-1146. 